\title{
Fundo público e políticas sociais nos Estados dependentes: considerações teóricas ${ }^{1}$
}

Public fund and social policies in dependent states: theoretical considerations

\section{Rodrigo de Souza Filho*}

\begin{abstract}
Resumo - Este estudo objetiva explicitar as principais determinações da dinâmica do Estado dependente e suas implicações no funcionamento do fundo público, principalmente no desenvolvimento de políticas sociais, tendo em vista a dinâmica estrutural da dependência caracterizada pela superexploração da força de trabalho. Concluise como hipótese teórica que, na América Latina, devido à estrutura da dependência, as demandas e necessidades sociais para a reprodução da força de trabalho são exponenciadas e os recursos do fundo público para atendê-las são estruturalmente restringidos.

Palavras-chave: teoria da dependência; Estado dependente; fundo público; políticas sociais.
\end{abstract}

Abstract - This study aims to explain the main determinations of dependent state dynamics and its implications in the operation of the public fund, especially its implications in the development of social policies, in view of the structural dynamics of dependence characterized by overexploitation of the workforce. It concludes as a theoretical hypothesis that in Latin America, due to the dependence structure, the demands and social needs for the reproduction of the labor force are exponentiated and the public fund resources to meet such demands and needs are structurally constrained.

Keywords: dependence theory; dependent state; public fund; social policies.

\footnotetext{
${ }^{1}$ Este artigo é produto do estágio pós-doutoral realizado com recursos da Capes — Processo BEX 7327/14-5, realizado no Departamento de Relaciones Sociales da Universidad Autónoma Metropolitana - Xochimilco, México, sob a supervisão do prof. dr. Jaime Osorio, no período de fevereiro de 2015 a agosto de 2015.

* Doutor em Serviço Social/UFRJ. Professor Associado da Faculdade de Serviço Social/UFJF. Correspondência: Rua Ivon José Cury, 1270. Portal da Torre, Juiz de Fora - MG. CEP: 36.037-467. Email: <rodrigosfilho@ig.com.br>
} 


\section{ApVistg all paUtg}

\} FUNDO PÚBLICO E POLÍTICAS SOCIAIS - SOUZA FH., R. \}

DOI: 10.12957/REP.2016.25401

\section{Introdução}

O presente estudo possui como objetivo explicitar as principais determinações da dinâmica do Estado dependente e suas implicações para o funcionamento do fundo público, principalmente aquelas que impactam o desenvolvimento das políticas sociais, tendo em vista a dinâmica estrutural da dependência, caracterizada pela superexploração da força de trabalho, conforme concebido por Marini (2005).

Dessa forma, iniciamos o referido artigo tecendo breves considerações acerca da dinâmica da acumulação capitalista, da função do fundo público e das políticas sociais. Em seguida, esboçamos uma caracterização geral da economia política da dependência, para, enfim, estabelecermos as devidas conexões entre o desenvolvimento do Estado dependente e suas implicações para a dinâmica do fundo público e das políticas sociais, em particular.

Cabe ainda destacar que, do ponto de vista político, este artigo se alinha ao entendimento de que

a defesa das políticas sociais universais e gratuitas e dos direitos sociais materializados por elas [se enquadra] na agenda anticapitalista, como mecanismos de transição e de reprodução da força de trabalho centrais nesse momento histórico, e como disputa do destino do fundo público [...]. [Dessa forma, visa] contribuir com a construção coletiva de um programa de esquerda, de transição efetiva para outra sociabilidade. (BEHRING, 2012, p. 154).

Para evitar qualquer tipo de dúvida em relação à perspectiva aqui adotada, não estamos advogando que a ação no campo das políticas sociais seja um elemento estratégico central, muito menos que esta ação seja "O" caminho da revolução. Apenas indicamos que é um ponto importante da agenda anticapitalista e que pode contribuir efetivamente com o acirramento das contradições da ordem do capital, além de atender de forma imediata às necessidades e demandas da classe trabalhadora.

\section{A dinâmica da acumulação capitalista, fundo público e políticas sociais: considerações gerais ${ }^{2}$}

Do ponto de vista teórico, tratar dialeticamente a questão das políticas sociais enquanto dever do Estado e direito de cidadania, ou seja, pública e gratuita (o que doravante denominaremos apenas de políticas sociais), significa, como já indicou Behring (1998), evitar o ecletismo, o economicismo, o estatismo e o politicismo. Portanto, devemos considerá-

${ }^{2}$ A concepção apresentada neste item encontra-se desenvolvida em Fundo público e políticas sociais no capitalismo: considerações teóricas (Souza Filho, 2016). 


\section{hevistg eml pallg}

\} FUNDO PÚBLICO E POLÍTICAS SOCIAIS - SOUZA FH., R. \}

DOI: $10.12957 /$ REP.2016.25401

la em sua totalidade. Neste sentido, deve-se analisar o momento predominante econômico e suas conexões dialéticas com as lutas de classes, a configuração do poder do Estado e da sua estrutura institucional (BOSCHETTI; BEHRING, 2006).

O presente trabalho concentra seus esforços em decodificar de forma mais precisa o momento econômico dos países dependentes para contribuir com as análises sobre as políticas sociais a partir dessa particularidade. Assim, ocupa-se, centralmente, da dimensão objetiva do tema, que se configura como o elemento estrutural, por excelência, no qual age constitutiva e permanentemente a dinâmica subjetiva das lutas de classes, do poder do Estado e de sua institucionalidade. Portanto, o trabalho proposto, embora inserido na perspectiva crítico-dialética, tem como objeto central a dimensão objetiva da temática. Assim, configura-se como um enfoque parcial para a compreensão da totalidade do fenômeno das políticas sociais.

Essa opção também se alinha à compreensão de que é a partir da dinâmica das relações sociais de produção que melhor podemos caracterizar e analisar as dinâmicas das lutas entre classes, frações e setores (Osorio, 2014), identificando de forma mais precisa as possiblidades, limites e perspectivas da intervenção social, do ponto de vista do trabalho. A ação efetiva das classes/frações/setores está ancorada pelas condições objetivas existentes; portanto, as alternativas não são ilimitadas, mas também não está determinada apenas uma possibilidade de atuação.

Seguindo essa trilha, para analisar a dimensão objetiva das políticas sociais devemos tratar a dinâmica do modo de produção capitalista, o capitalismo dependente, o padrão de reprodução do capital, a política econômica e a estrutura da política social enquanto determinações que interagem dialeticamente.

O presente trabalho, como sinalizado anteriormente, dedica-se ao debate sobre o capitalismo dependente e suas implicações para a dinâmica do fundo público e das políticas sociais (o que será abordado nas seções seguintes). Nesse sentido, pelas limitações do artigo, não trataremos das outras determinações indicadas (dinâmica do modo de produção capitalista, o padrão de reprodução do capital, a política econômica e a estrutura da política social); apenas abordaremos de forma sintética nossa concepção acerca do fundo público e sua relação com as políticas sociais.

Entendemos que a questão da distribuição da renda e da repartição do valor são os elementos centrais, do ponto de vista da economia política, para analisarmos a questão do fundo público no quadro do capitalismo monopolista.

Conforme destaca Marx (1986, p. 286), considerando o produto anual de uma nação, constituído por todo o capital investido naquele período determinado, ou seja, o capital constante, o capital variável e a maisvalia, se descontarmos o valor relativo à reposição do capital constante 


\section{ADVistg all paUtg}

\} FUNDO PÚBLICO E POLÍTICAS SOCIAIS - SOUZA FH., R. \}

DOI: $10.12957 /$ REP.2016.25401

utilizado para a produção, o que resta refere-se à renda/receita bruta ou renda/receita nacional. Ou seja, à distribuição básica da sociedade expressa em capital variável/salário e mais-valia, formando o valor novo produzido no referido ano.

Nessa divisão da renda nacional ocorre o conflito central entre as classes sociais antagônicas no capitalismo, a saber, a luta para ampliar o valor do trabalho necessário, reduzindo o valor relacionado ao trabalho excedente e, ao contrário, a luta do capital para ampliar a mais-valia, reduzindo o valor do trabalho necessário. $O$ resultado de tal luta de classes determina a distribuição da renda nacional. Estabelecida essa demarcação da renda nacional, no campo capitalista ocorre uma luta entre as diferentes frações de classe sobre a repartição da mais-valia.

Devido à expansão da intervenção do Estado na sociedade, esse processo de disputa da riqueza socialmente produzida ganha um contorno qualitativamente diferenciado em função da consequente expansão do fundo público. A disputa travada na sociedade entre as classes e frações de classes pela riqueza produzida passa agora a ocorrer também na esfera estatal em torno do fundo público, principalmente em dois momentos fundamentais: na definição da tributação e do gasto público. Qualitativamente falando, essa disputa busca compensar, de alguma forma, as perdas, ou ampliar os ganhos conquistados no âmbito da luta social entre as diferentes classes e frações de classes, realizada em torno da riqueza produzida (MANDEL, 1982).

Assim, entendemos que o complexo processo de disputa da riqueza socialmente produzida fica mais inteligível e mais adequado à dinâmica da fase monopólica do capitalismo devido à mediação central do Estado, através do fundo público, para garantir a produção e reprodução das relações sociais capitalistas.

Dessa forma, entendemos, por exemplo, que a formulação da categoria excedente (BARAN; SWEEZY, 1982), apesar de ser utilizada para explicitar diferentes gastos que passam a ser necessários para o processo de reprodução do capital em sua fase monopolista, na medida em que ocorre um crescimento quantitativo desses gastos que impacta qualitativamente a forma de produção e reprodução das relações sociais, não favorece a análise da dimensão política, via mediação do Estado/fundo público, que pode redefinir a dinâmica da distribuição da renda e da repartição da mais-valia ${ }^{3}$. Mesmo porque, como indicam os autores, a "geração e absorção dos excedentes sob as condições do capitalismo monopolista [...] é a forma mais útil e esclarecedora para analisar o funcionamento puramente econômico do sistema" (BARAN; SWEEZY, 1982, p. 12 - tradução livre).

${ }^{3}$ Cabe destacar que Marini (2012), ao tratar do ciclo do capital na economia dependente, também recorre à mediação do Estado para melhor interpretar o processo de arrecadação e gasto público que influencia o ciclo do capital na primeira fase da circulação. 
O objeto dos autores é a análise puramente econômica do sistema, enquanto nosso interesse implica em entender as articulações entre o econômico e o político, via mediação do Estado/fundo público, e suas consequências; em especial, no campo da distribuição da riqueza.

Por outro lado, ao substituir a categoria "mais-valia" por "excedente $^{\prime 4}$, por entenderem que a mais-valia, ao se identificar diretamente com o lucro, juro e renda não permite captar outros gastos que deixaram de ser secundários, na medida da necessidade da produção e reprodução de uma sociedade capitalista monopolista desenvolvida, os autores, conforme analisa Mandel (2010), acabam buscando combinar Keynes com Marx. Com isso, cometem equívocos de análise sobre o desenvolvimento da economia capitalista em sua fase monopólica ${ }^{5}$.

Dessa forma, o caminho seguido pelos autores se afasta de nossas pretensões de análise, tanto do ponto de vista econômico, visto que consideramos fundamental entender a dinâmica da distribuição e repartição a partir da análise da relação entre o valor da força de trabalho e da mais-valia, quanto do ponto de vista político, já que consideramos essencial desvelar a luta de classes que se desenvolve na sociedade civil e na esfera estatal em torno da riqueza produzida. Como assevera Mandel (2010, p. 5), acerca da formulação de Baran e Sweezy,

Pondo de lado na sua análise do capitalismo monopolista a luta contínua da classe capitalista por manter e aumentar a taxa de exploração da classe obreira, [...] colocam todo o seu conceito econômico do funcionamento atual do sistema capitalista fora da realidade das forças sociais em presença, isto é, fora do domínio da luta de classes.

A centralidade, portanto, da teoria do valor desenvolvida por Marx é o caminho pelo qual continuaremos desenvolvendo nossas reflexões. Inserido em tal campo teórico-metodológico, Oliveira (1998, p. 53), de forma precisa, sintetiza sua tese sobre o fundo público ${ }^{6}$ :

Ele [fundo público] não é, portanto, a expressão apenas de recursos estatais destinados a sustentar ou financiar a acumulação de capital; ele é um mix que se forma dialeticamente e representa na mesma unidade, contém na mesma unidade, no mesmo movimento, a razão do Estado que é sociopolítica, ou pública, se quisermos, e a razão dos capitais que é privada. O fundo público, portanto, busca explicar

\footnotetext{
${ }^{4}$ Baran e Sweezy (1982, p. 13), formulam, de forma sintética, que "o excedente econômico [...] é a diferença entre o que uma sociedade produz e os custos de sua produção. A magnitude do excedente é um índice de produtividade e de riqueza, da liberdade que tem uma sociedade para alcançar as metas que fixou a si mesma. A composição do excedente mostra como faz o uso desta liberdade: quanto investe em ampliar sua capacidade produtiva, quanto consome, em diversas formas, quanto desperdiça e de que maneira".

${ }^{5}$ Para o aprofundamento da crítica às formulações sobre a categoria excedente de Baran e Sweezy (1982), ver o texto de Mandel (2010), A teoria do valor-trabalho e o capitalismo monopolista.

${ }^{6}$ Sobre as polêmicas a respeito da formulação de Oliveira (1998a) acerca do fundo público, ver a síntese de Salvador (2010) e as questões abordadas por Souza Filho (2016).
} 


\section{ADVistg all paUtg}

\} FUNDO PÚBLICO E POLÍTICAS SOCIAIS - SOUZA FH., R. \}

DOI: $10.12957 /$ REP.2016.25401

a constituição, a formação, de uma nova sustentação da produção e da reprodução do valor, introduzindo, mixando, na mesma unidade, a forma valor e o antivalor, isto é um valor que busca a mais-valia e o lucro, e uma outra fração, que chamo de antivalor, que busca não valorizar-se per se, pois não é capital, ao juntar-se ao capital, sustenta o processo de valorização do valor.

Com essa formulação, Oliveira (1998a; 1998b), ao se deter à dinâmica do fundo público, consegue teorizar, a partir de sua expansão na fase do capitalismo tardio, sua constituição como um mix de recursos que viabiliza diretamente a produção de valor (empresas estatais). Além disso, indiretamente, através de aportes do fundo público ao capital constante (subsídios para a produção, desenvolvimento da ciência e tecnologia, juros subsidiados...) e ao capital variável (políticas sociais - efetivação do salário indireto). Nesse sentido, ele mostra a relação dialética entre a dinâmica da acumulação capitalista e as políticas sociais, via mediação do fundo público. Ademais, o autor destaca com propriedade a contradição desse processo, indicando a possibilidade da "retração da base social da exploração" a partir da expansão do salário indireto.

Entretanto, cabe ressaltar que a elevação do salário para além do seu valor encontra limites na própria dinâmica de acumulação capitalista, relacionados ao limite mínimo que o lucro capitalista pode atingir sem comprometer a continuidade da reprodução ampliada, apesar de, como adverte Marx (1996c, p. 115 - grifos no original), "no que se refere ao lucro, não existe nenhuma lei que lhe fixe o mínimo. Não podemos dizer qual seja o limite extremo de sua baixa [...]. Porque, embora possamos fixar o salário mínimo, não podemos fixar o salário máximo". No entanto, como o próprio autor complementa, "uma alta geral da taxa de salários acarretaria uma baixa da taxa geral de lucro" (MARX, 1996c, p. 118). Romper esse limite significa romper com a lógica da política social enquanto instrumento da ordem do capital e, portanto, revolucionar o modo de produção capitalista.

Como vimos, o fundo público se materializa a partir de dois movimentos: o da arrecadação e o do gasto público. Bresser-Pereira (1982), apesar de trabalhar numa concepção distinta da tratada neste artigo, desenvolve uma descrição extremamente útil para pensarmos o fundo público a partir do movimento de arrecadação e de gasto público no quadro do capitalismo tardio.

Do ponto de vista da despesa, Bresser-Pereira (1982) propõe uma classificação pautada em cinco itens: segurança e administração (G), consumo social básico (UB), consumo social de luxo (UL), acumulação estatal (A) e subsídios à acumulação privada (S). Dessa forma, o total do gasto público refere-se ao somatório dessas diferentes despesas.

Como as despesas do Estado beneficiam uma ou outra classe social, o autor infere que o salário total do trabalhador seria igual a salário 


\section{hevistg eml pallg}

\} FUNDO PÚBLICO E POLÍTICAS SOCIAIS - SOUZA FH., R. \}

DOI: 10.12957/REP.2016.25401

mais consumo social básico. A renda total das camadas média e alta e dos capitalistas seria o somatório dos salários dos tecnoburocratas mais lucro, mais consumo social de luxo, mais subsídios ao capital e mais segurança e administração do Estado, na medida em que essas despesas, ao manterem a ordem social, "beneficiam principalmente as classes dominantes, ou seja, os capitalistas e a alta tecnoburocracia podem ser consideradas salários indiretos" (BRESSER-PEREIRA, 1982, p. 21).

Nesse sentido, as despesas do Estado possuem efeito distributivo ou concentrador, dependendo do quantum que será destinado ao salário indireto e à renda dos capitalistas e das camadas altas de tecnoburocratas em relação aos impostos arrecadados de cada classe e fração de classe.

Assim, considerando um orçamento equilibrado, se a diferença entre o consumo social básico e o imposto que incide sobre os trabalhadores for positivo, o orçamento terá uma tendência à distributividade. No entanto, caso seja positiva a diferença entre o consumo de luxo mais subsídios ao capital, mais segurança e administração do Estado e os impostos que incidem sobre os tecnoburocratas e os capitalistas, a tendência da estrutura do orçamento público será concentradora.

Para que ocorra a "retração da base social da exploração", nos termos de Oliveira (1998a), será necessário que a tendência do fundo público se expresse na primeira hipótese. Ou seja, os gastos públicos voltados para o consumo social básico devem ser maiores que os impostos que incidem sobre a classe trabalhadora. Em contraparte, as despesas públicas voltadas para segurança e administração, consumo de luxo e subsídios ao capital devem ser menores que os impostos que incidem sobre o capital e a renda das camadas altas da tecnoburocracia, na mesma proporção da primeira diferença, em se tratando de um orçamento equilibrado.

Dessa forma, o item seguinte aborda a dinâmica do capitalismo dependente, de modo que possamos analisar, em seguida, seus impactos na estrutura de constituição do fundo público em relação à arrecadação e à despesa dos Estados dependentes.

\section{A economia política da dependência: caracterização geral}

Tratar da economia política da dependência significa, por um lado, situá-la no contexto histórico de seu surgimento, buscando explicitar a conjuntura econômica e social da época, as influências políticas e as questões teóricas que se encontravam em pauta no momento de sua gênese. Por outro lado, é necessário apresentar, com o máximo de precisão, as principais determinações que constituem tal teoria.

Vejamos, brevemente, o primeiro aspecto indicado para, em seguida, tratarmos do que se configura como o objeto de tal item: a caracterização do capitalismo dependente. 


\section{ADVistg all paUtg}

\} FUNDO PÚBLICO E POLÍTICAS SOCIAIS - SOUZA FH., R. \}

DOI: 10.12957/REP.2016.25401

Do ponto de vista político, social e econômico, o surgimento da produção sobre a dependência da América Latina está inserido na conjuntura da década de 1960. O processo de industrialização que se intensifica na região a partir dos anos de 1950 não logra o desenvolvimento esperado por diferentes setores sociais, na medida em que se mantém um quadro acirrado de desigualdade, social e economicamente. A industrialização realizada não supera os mecanismos que subordinam as economias latinoamericanas aos países imperialistas, quais sejam: pobreza, baixo desenvolvimento do Departamento I da economia (produção de bens de produção), produção de bens de luxo em detrimento de bens salário, no Departamento II, e manutenção de estrutura agrária concentradora de terra e da dependência tecnológica. Enfim, uma série de traços que faz com que se perpetue a dinâmica de acumulação não autônoma de desenvolvimento em relação aos países centrais, bem como a desigualdade social e econômica interna.

Simultaneamente a essa situação, a vitória da Revolução Cubana (1959) desencadeia um clima na região que fortalece o pensamento e a ação política no sentido de buscar novos caminhos teórico-práticos para viabilizar o desenvolvimento econômico e social da América Latina. Nesse contexto, a teoria desenvolvimentista produzida pela Comissão Econômica para América Latina e Caribe (Cepal), tendo como principais expoentes Raúl Prebisch e Celso Furtado, foi alvo de avaliações críticas, abrindo caminho para o que se convencionou chamar de teorias da dependência.

O projeto de industrialização não logrou o êxito que o nacionaldesenvolvimentista cepalino trazia como expectativa. A crescente importação de produtos industrializados, principalmente bens de produção, para viabilizar a industrialização gerou forte pressão nas divisas e exigiu uma participação crescente do capital estrangeiro no financiamento e investimento do desenvolvimento industrial da América Latina, o que não estava previsto no projeto de caráter autônomo defendido pelos teóricos da Cepal (MARTINS, 2011).

Podemos dizer que, concomitantemente, após a crise do projeto teórico-político da Cepal, duas abordagens distintas da dependência vão se desenvolvendo, buscando compreender as particularidades do capitalismo latino-americano, entendendo que os problemas de nosso desenvolvimento não se encontram somente vinculados a fatores externos.

A primeira delas é a vertente eclética (marxo-weberiana) liderada por Fernando Henrique Cardoso e Enzo Faletto, a partir de obra conjunta, publicada em 1969, em circulação interna desde 1966, intitulada Dependência e desenvolvimento na América Latina.

A segunda é a vertente marxista que, a partir dos trabalhos de André Gunder Frank, Theotônio dos Santos, Vânia Bambirra, Orlando Caputo e Roberto Pizarro, encontra sua formulação considerada mais consistente e madura na obra Dialética da dependência, de Ruy Mauro Marini, 


\section{hevistg eml pallg}

\} FUNDO PÚBLICO E POLÍTICAS SOCIAIS - SOUZA FH., R. \}

DOI: 10.12957/REP.2016.25401

publicada em 1973. Tendo como referência central essa obra de Marini (2005), traçaremos as determinações fundamentais do capitalismo dependente.

No esforço de realizar uma breve síntese sobre a dinâmica da dependência, apresentaremos três dimensões constitutivas do capitalismo latino-americano: transferência de valor, superexploração da força de trabalho e ruptura do ciclo de capital.

A questão da dependência é tratada no campo da teoria marxista da dependência (TMD), principalmente a partir da concepção de Lenin sobre o imperialismo (Imperialismo fase superior do capitalismo), mas é influenciada também pelo trabalho de Paul Baran (Economia política do desenvolvimento). Ou seja, essa questão é analisada tendo como perspectiva uma visão de totalidade do modo de produção capitalista enquanto um sistema de produção e reprodução mundial. As economias nacionais dos países dependentes se inserem na dinâmica das relações capitalistas que se estruturam de forma hierárquica e heterogênea, subordinada às dos países imperialistas. De acordo com Marini (2005, p. 141), a dependência deve ser entendida como:

[...] uma relação de subordinação entre nações formalmente independentes, em cujo marco as relações de produção das nações subordinadas ou recriadas para assegurar a reprodução ampliada da dependência. A consequência da dependência não pode ser, portanto, nada mais do que maior dependência e sua superação supõe necessariamente a supressão das relações de produção nela envolvida.

Inserida nesse quadro teórico, a transferência de valor trabalhada por Marini (2005) deve ser compreendida, de forma geral, como uma superação dialética da crítica cepalina à tese ricardiana da vantagem comparativa como base do comércio internacional. Essa superação acompanha a análise da Cepal quanto à existência de uma hierarquia e heterogeneidade nas relações econômicas internacionais. No entanto, requalifica o conteúdo que funda essas relações a partir da tradição marxista.

Dessa forma, a inserção dos países dependentes na dinâmica do capitalismo é analisada a partir de uma divisão internacional do trabalho, em que cabe à periferia, num primeiro momento, enquanto economia exportadora ainda não industrializada, a produção de matérias-primas e gêneros alimentícios. Do ponto de vista substantivo, essa inserção contribuirá para que o deslocamento do eixo da acumulação dos países industrializados passe da produção de mais-valia absoluta para a de mais-valia relativa (MARINI, 2005).

Após a consolidação da industrialização dos países dependentes (anos 1950), agrega-se à produção de matérias-primas e gêneros alimentícios a produção de bens de consumo não duráveis. Além dessa característica, os bens de consumo duráveis são produzidos a partir da associação 


\section{ADVistg all paUtg}

\} FUNDO PÚBLICO E POLÍTICAS SOCIAIS - SOUZA FH., R. \}

DOI: 10.12957/REP.2016.25401

com o capital internacional (empréstimo, investimento externo direto, pagamento de royalties...) e/ou comprando mercadorias do exterior, principalmente relacionadas ao capital constante, necessárias para a produção desses bens (MARINI, 2005; AMARAL; CARCANHOLO, 2012).

Esse processo de inserção subordinada da economia latino-americana no sistema mundial capitalista que, como vimos, contribui para a passagem da acumulação dos países industriais baseada na produção de mais-valia absoluta para a de mais-valia relativa, sustenta-se na transferência de valor produzido nas economias dependentes para as economias centrais. Ou seja, parte do mais valor produzido nos países periféricos não é apropriada por eles, mas sim pelas economias desenvolvidas.

Marini (2005) identifica dois mecanismos que efetivam a transferência de valor: a produção de mais-valia extraordinária, baseada na maior produtividade, e o monopólio de produção. Tanto um quanto o outro possibilitam que os bens produzidos pelos países industrializados sejam vendidos por um preço acima de seu valor, provocando nos países importadores a necessidade de dispor de mais valor para obter tais bens. Essa troca desigual promove, portanto, a transferência de valor dos países dependentes para os países imperialistas ${ }^{7}$. Tal movimento tem como consequência a redução do excedente disponível para a dinâmica interna da produção e reprodução das relações sociais dos países periféricos.

Do ponto de vista do capital, a consequência imediata é a redução da quantidade de mais valor que pode ser apropriado privadamente, seja para o consumo do capitalista, seja para a reprodução e ampliação do capital. Essa situação gera a necessidade estrutural de compensar a perda da mais-valia ocasionada pela transferência de valor. Conforme explicita Marini (2005, p. 154):

Vimos que o problema colocado pela troca desigual para a América Latina não é precisamente a de se contrapor à transferência de valor que implica, mas compensar a perda da mais-valia, e que, incapaz de impedi-la no nível das relações de mercado, a reação da economia dependente é compensá-la no plano da produção interna.

Nesse sentido, este autor defende a tese de que a dinâmica da dependência implica na configuração da superexploração da força de trabalho como elemento estrutural do processo de produção e reprodução das relações sociais dos países periféricos. Em suas palavras:

Chamada para contribuir com a acumulação de capital com base na capacidade produtiva do trabalho, nos países centrais, a América Latina teve de fazê-lo mediante uma acumulação baseada na superexploração do trabalhador. É nessa contradição que se radica a essência da dependência latino-americana. (MARINI, 2005, p. 162).

${ }^{7}$ Marini (1979) aprofunda essa questão em Plusvalía extraordinaria y acumulación de capital. 


\section{hevistg eml pallg}

\} FUNDO PÚBLICO E POLÍTICAS SOCIAIS - SOUZA FH., R. \}

DOI: $10.12957 / R E P .2016 .25401$

De acordo com Marini (2005), diante da sangria de mais valor dos países dependentes e da impossibilidade/dificuldade de aumento de produtividade (não acesso à tecnologia e não condição de desenvolver tecnologia de forma endógena, devido, entre outras coisas, à necessidade de altos investimentos), a elevação da taxa de mais-valia é realizada à custa da extração de mais trabalho não remunerado de seus operários. Tal elevação da extração do mais trabalho é realizada através da violação do valor da força de trabalho ${ }^{8}$. Sendo assim, o que caracteriza a superexploração da força de trabalho nos países dependentes é seu caráter estrutural de violação do valor da força de trabalho como dinâmica da produção e reprodução das relações sociais capitalistas. Isto é, a superexploração da força de trabalho é uma particularidade do processo de acumulação capitalista que ocorre nas formações sociais dependentes ${ }^{9}$.

Visando caracterizar a superexploração, Osorio (2013, p. 63) destaca que "a superexploração é a violação do valor da força de trabalho e que ela se realiza sob diversas formas, algumas violando diretamente o valor diário da força de trabalho e outras, mediadas, violando seu valor total". Sintetizando a formulação de Marini, apresentam-se as três formas de efetivação da violação do valor da força de trabalho: compra da força de trabalho por um salário inferior a seu valor, prolongamento anormal da jornada de trabalho sem contraparte de salário (o autor adverte, no entanto, que acima de um determinado patamar, mesmo existindo contraparte salarial, este nunca será suficiente para repor o desgaste do trabalhador) e intensificação do trabalho (também nesse caso existe um ponto a partir do qual os incrementos salariais não permitem repor o desgaste provocado pela referida intensificação).

De acordo com Marini (2005, p. 157), "em termos capitalistas, esses mecanismos (que ademais podem se apresentar, e normalmente se apresentam, de forma combinada) significam que o trabalho é remunerado abaixo de seu valor e correspondem, portanto, a uma superexploração do trabalho". Num esforço de síntese, para Carcanholo (2013, p. 83):

i) a superexploração é uma categoria que não pode ser confundida com as distintas formas existentes no capitalismo para elevar a taxa de mais-valia (taxa de exploração), ainda que só possa se materializar por meio destas formas; e ii) a superexploração é uma categoria específica da economia dependente - portanto, em um menor nível de abstração do que as leis gerais do modo de produção capitalista -, mesmo que, evidentemente, enquanto forma de elevação da taxa

\footnotetext{
${ }^{8}$ A possibilidade da superexploração é indicada por Marx (1996a, p. 290; 430) no Livro I, vol. I, e no Livro III (MARX, 2008, p. 313-314). Para uma análise acurada dessas indicações marxianas e a categoria superexploração, ver Osorio (2013).

${ }^{9}$ É importante destacar, conforme sublinha Marini (1978), que a superexploração da força de trabalho é estimulada pela transferência de valor que ocorre devido à troca desigual, mas não deriva dela; deriva da busca do lucro e se baseia na formação da superpopulação relativa.
} 


\section{ADVistg all paUtg}

\} FUNDO PÚBLICO E POLÍTICAS SOCIAIS - SOUZA FH., R. \}

DOI: 10.12957/REP.2016.25401

de mais-valia, opere em qualquer economia capitalista, mesmo nas centrais.

A terceira dimensão a registrar refere-se à ruptura do ciclo do capital que ocorre nos países dependentes e que bloqueia o desenvolvimento industrial autônomo.

Em termos gerais, conforme analisa Osorio (2009), a ruptura do ciclo do capital indica que a produção mais dinâmica do capitalismo dependente não está voltada para a produção de bens salariais. Essa ruptura se fez presente, de forma distinta, tanto no período agroexportador, quanto na fase industrial dos países periféricos, e está dialeticamente articulada à dinâmica da superexploração da força de trabalho.

A consequência econômica mais direta da superexploração da força de trabalho é o fato de os produtores não se efetivarem como consumidores centrais das mercadorias produzidas. Ou seja, a violação do valor da força de trabalho, por motivos óbvios, impede que os trabalhadores se tornem efetivos consumidores.

No período agroexportador, a ruptura do ciclo do capital ocorre na medida em que a economia se orienta para a produção de gêneros alimentícios e matérias-primas necessárias à consolidação da acumulação, estando esta última baseada na mais-valia relativa dos países industrializados. Portanto, por um lado, o eixo dinâmico da economia está voltado para a exportação e, por outro, não há estímulo, na medida da superexploração, ao desenvolvimento da produção para os trabalhadores. O consumo de bens de luxo para os capitalistas e as camadas altas e médias nativas é provido pela importação, alimentando a dinâmica da transferência de valor.

Dessa forma, nos países dependentes a circulação se separa da produção e se efetiva no mercado externo, "o consumo individual do trabalhador não interfere na realização do produto, ainda que determine a taxa de mais-valia". Como consequência, a tendência é explorar ao máximo a força de trabalho (MARINI, 2005, p. 164).

Em um período da industrialização associada ao capital internacional, a existência de um mercado interno formado por capitalistas e camadas alta e média da população promove o desenvolvimento da produção interna de bens de luxo, mantendo, ainda, a produção de gêneros alimentícios e matérias-primas para os países centrais. A importação de bens de produção se intensifica. Assim, a transferência de valor se mantém pela lógica anterior, mas agrega a ela, principalmente, a transferência via emissão de lucros das filiais para as matrizes, o pagamento de juros a credores internacionais e o intercâmbio desigual relacionado à importação de bens de produção. Essa dinâmica reproduz a superexploração da força de trabalho, apesar de criar um segmento de trabalhador mais bem remunerado que será inserido no mercado de consumo de bens não duráveis. 
De forma precisa, Marini (2005, p. 170-171) sintetiza:

No início da industrialização, a participação dos trabalhadores na criação da demanda não joga, portanto, um papel significativo na América Latina [...] Partindo então do modo de circulação que caracterizara a economia exportadora, a economia industrial dependente reproduz, de forma específica, a acumulação de capital baseada na superexploração do trabalhador. Em consequência, reproduz também o modo de circulação que corresponde a este tipo de acumulação, ainda que de maneira modificada: já não é a dissociação entre a produção e a circulação de mercadorias em função do mercado mundial o que opera, mas a separação entre a esfera alta e a esfera baixa da circulação no interior mesmo da economia, separação que, ao não ser contraposta pelos fatores que atuam na economia capitalista clássica, adquire uma caráter muito mais radical.

Considerando as três dimensões abordadas, que dialeticamente determinam as condições objetivas de desenvolvimento da economia política da dependência, transferência de valor, superexploração da força de trabalho e ruptura do ciclo de capital, tendo a superexploração como o eixo estrutural, podemos avançar agora para apontar, a partir de tais parâmetros, indicativos teóricos que nos ajudem a compreender a dinâmica do fundo público e das políticas sociais na América Latina.

\section{Estado dependente: implicações para a dinâmica do fundo público e das políticas sociais}

\subsection{Dependência e configuração da "questão social", do Estado e de seu aparato}

A abordagem crítica da questão social deve ser apreendida conforme apresentada por lamamoto (2001, p. 16-17):

[...] conjunto das expressões das desigualdades sociais engendradas na sociedade capitalista madura, impensáveis sem a intermediação do Estado. Tem sua gênese no caráter coletivo da produção, contraposto à apropriação privada da própria atividade humana - o trabalho -, das condições necessárias à sua realização, assim como de seus frutos. [...] A questão social expressa, portanto, disparidades econômicas, políticas e culturais das classes sociais, mediatizadas por relações de gênero, características étnico-raciais e formações regionais, colocando em causa as relações entre amplos segmentos da sociedade civil e o poder estatal.

Mas a questão social também tem uma dimensão fundamentalmente política: representa a luta dos trabalhadores, por meio de pressões 


\section{ADVistg all paUtg}

\} FUNDO PÚBLICO E POLÍTICAS SOCIAIS - SOUZA FH., R. \}

DOI: $10.12957 /$ REP.2016.25401

ao Estado e ao patronato, por um conjunto de demandas que vão desde o acesso a direitos, até a apropriação da riqueza socialmente produzida ${ }^{10}$.

Do ponto de vista teórico, o fundamento mais abstrato da "questão social" na sociedade capitalista encontra-se na formulação marxiana da Lei geral da acumulação capitalista:

Ela ocasiona uma acumulação de miséria correspondente à acumulação de capital. A acumulação da riqueza num polo é, portanto, ao mesmo tempo, a acumulaçã̃o de miséria, tormento de trabalho, escravidão, ignorância, brutalização, e degradação moral no polo oposto, isto é, do lado da classe que produz seu próprio produto como capital. (MARX, 1996b, p. 275).

Em outras palavras, o movimento de reprodução ampliada do capital exige a apropriação privada da riqueza produzida através da exploração da força de trabalho para que parte da mais-valia apropriada retorne à produção na perspectiva de valorização do valor, visando à expansão da acumulação. Esse movimento implica no investimento em meios de produção para que se potencialize a produtividade da força de trabalho. Por consequência, desenvolve-se um processo de concentração e centralização de capital, com acréscimo do capital constante em quantidade maior que o do capital variável. Assim, reduz-se, relativamente, a necessidade de trabalhadores na unidade de produção, gerando o que Marx (1996b, p. 261) qualifica de superpopulação relativa, ou seja, "uma população trabalhadora adicional, relativamente supérflua ou subsidiária, ao menos no concernente às necessidades de aproveitamento por parte do capital".

Essa superpopulação relativa se expressa de diferentes formas: Iíquida, latente e estagnada (MARX, 1996b). A líquida refere-se à parte da superpopulação fluente, que se encontra ora empregada, ora desempregada, ao sabor das conjunturas econômicas. Em termos estruturais, mesmo que ocorra um crescimento de ocupados dessa fração da superpopulação, sempre será um crescimento em proporção menor à escala da produção.

A parte da superpopulação que fica disponível para ser acessada pela indústria em determinadas circunstâncias do desenvolvimento econômico é a latente. Essa fração da superpopulação se identifica com os trabaIhadores rurais, na medida em que a produção capitalista incorpora a agricultura. Diferentemente do que ocorre com os trabalhadores da indústria, a agricultura, ao ser apropriada pelo capital, não cria novos polos de atração para o trabalhador rural. Esse processo leva à queda da quantidade de trabalhadores rurais, de forma absoluta, necessários à produção capitalista. A população rural, portanto, está sempre potencialmente disponível para se

${ }^{10}$ Para um mapeamento das determinações teóricas e históricas da categoria "questão social", ver, também, Netto (2001). 


\section{hevistg eml pallg}

\} FUNDO PÚBLICO E POLÍTICAS SOCIAIS - SOUZA FH., R. \}

DOI: 10.12957/REP.2016.25401

transformar em trabalhador urbano, dependendo das condições conjunturais. Torna-se necessário manter, de forma permanente, tal situação para atender a determinadas demandas do capital industrial. "O trabalhador rural é, por isso, rebaixado para o mínimo do salário e está sempre com um pé no pântano do pauperismo" (MARX, 1996b, p. 272).

A superpopulação estagnada caracteriza-se por ser aquela que se encontra em ocupações irregulares. Conforma-se como um campo de reserva de força de trabalho para o capital e, devido à sua condição de vida estar abaixo do nível médio da classe trabalhadora, apresenta-se disponível para determinados ramos de exploração do capital. "É caracterizada pelo máximo tempo de serviço e mínimo de salário" (MARX, 1996b, p. 272).

Por fim, o autor de $O$ capital indica que o sedimento da superpopulação relativa é constituído pela população que vive em condições de pauperismo. Descontando o lumpemproletariado (vagabundos, delinquentes, prostitutas), essa camada divide-se em três categorias: aptos ao trabalho, órfãos e crianças indigentes e incapacitados. Sintetizando a caracterização do pauperismo, Marx (1996b, p. 273) afirma:

O pauperismo constitui o asilo para inválidos do exército ativo de trabalhadores e o peso morto do exército industrial de reserva. Sua produção está incluída na produção da superpopulação relativa, sua necessidade na necessidade dela, e ambos constituem uma condição de existência da produção capitalista e do desenvolvimento da riqueza.

Considerando a estrutura da dependência fundada na superexploração da força de trabalho, a Lei Geral da Acumulação é exponenciada. "Poderíamos afirmar que nelas [economias dependentes] a capacidade do capital mundial e local de criar população excedente e miséria se potencializa" (OSORIO, 2012, p. 129 - tradução livre).

Se, no quadro da exploração da força de trabalho, já ocorre a produção da superpopulação relativa, em suas diferentes frações, o pauperismo como sedimento dessa superpopulação é um processo absoluto e/ ou relativo de crescimento da pobreza e miséria, de um lado, e de riqueza, do outro. Nas condições de violação do valor da força de trabalho, essa polarização se intensifica ainda mais e a situação da classe trabalhadora piora significativamente.

Nesse sentido, estruturalmente, sobretudo em sua gênese, nos países dependentes a dimensão da superpopulação relativa em proporção à po-pulação trabalhadora em geral é muito maior do que a dos países centrais. Além disso, em seu interior, o sedimento pauperizado e as frações latente e estagnada inclinam-se a se elevar a proporções gigantescas frente aos trabalhadores ativos e à fração líquida da superpopulação. Essa configuração, conforme sublinham Paiva e Ouriques (2009, p. 126), 
implica o reconhecimento de uma especificidade [da política social] latino-americana: na medida em que a maioria da força de trabalho na América Latina é submetida à superexploração, os direitos sociais a ela destinados só podem corresponder a esquemas próprios, ao contrário das configurações diretamente contributivas, conforme modelos clássicos das sociedades que experimentaram o pleno emprego ou que se encontram no centro do mercado mundial.

Por outro lado, a ruptura do ciclo do capital faz com que a produção se destine ao mercado externo e/ou ao consumo de bens de luxo, não objetivando tornar os produtores consumidores das mercadorias produzidas, enquanto eixo dinâmico da acumulação. Ou seja, o fato de a classe trabalhadora não ser necessária, substantivamente, para a realização do mais valor intensifica o cenário traçado acima. Assim, os contornos da questão social, do ponto de vista das condições de vida da classe trabaIhadora, tendem a apresentar tons de dramaticidade e tragédia.

A outra questão fundamental que devemos tratar na presente seção diz respeito à questão do Estado dependente e de seu aparato. A distinção entre Estado e aparato apresentada por Osorio (2014), a partir do fundamento marxiano, é extremamente pertinente para a análise do Estado em seu conjunto, incorporando suas contradições, limites e possibilidades, no sentido de um maior ou menor atendimento a interesses do trabalho, desde que não inviabilize a acumulação de capital.

Marx (1996d, p. 52) mostra que o Estado deve ser analisado a partir da constituição da sociedade civil:

na produção social da própria vida, os homens contraem relações determinadas, necessárias e independentes de sua vontade, relações de produção estas que correspondem a uma etapa determinada de desenvolvimento de suas forças produtivas materiais. A totalidade dessas relações de produção forma a estrutura econômica da sociedade, a base real sobre a qual se levanta uma superestrutura jurídica e política, e à qual correspondem formas sociais determinadas de consciência.

O Estado, dessa forma, não é a expressão da universalidade, como diria Hegel (1997), mas sim a expressão das relações sociais de produção existentes na sociedade capitalista, portanto, uma "universalidade alienada". No caso da sociedade capitalista, o Estado será estruturado tendo como base a relação de exploração estabelecida pelo capital. O Estado, assim, representa a dominação de classe presente na sociedade civil para garantir a manutenção e a reprodução das relações sociais estabelecidas pela ordem do capital.

Osorio (2014, p. 67 - tradução livre), partindo desse entendimento, caracteriza o Estado como "condensação de relações sociais de poder, domínio, e aquelas que conformam comunidade, imperantes em 


\section{hevistg eml pallg}

\} FUNDO PÚBLICO E POLÍTICAS SOCIAIS - SOUZA FH., R. \}

DOI: 10.12957/REP.2016.25401

uma sociedade". O aparato do Estado, para o autor, se configura como a "coisificação" do Estado, ou seja, a materialização das relações sociais de poder e domínio e das relações que permitem a construção de comunidade, realizada através de um conjunto de instituições, um corpo de leis e o pessoal do Estado. Além disso, o autor afirma que, no capitalismo, a classe dominante tende a delegar a administração do aparato do Estado para outros setores sociais de outras classes sociais.

Complementando, a partir das reflexões de Souza Filho (2011), podemos dizer que o aparato do Estado dependente, enquanto ordem administrativa, de maneira geral, sofre influência advinda das determinações oriundas das relações sociais de produção. Por outro lado, a ordem administrativa como instrumento de materialização da dominação de classe presente no Estado sofre as interferências da formação social específica.

A determinação fundamental de uma ordem administrativa deve ser encontrada, portanto, na estrutura de classes da sociedade, na medida em que são os interesses antagônicos de classes que conformam os conflitos substantivos numa sociedade, exigindo a intervenção do Estado através de sua ordem administrativa (MARX, 1996d).

A partir dessa compreensão teórica, o desenvolvimento do aparato do Estado dependente está vinculado às ações administrativas necessárias para operacionalizar a expansão de nosso capitalismo dependente, desde o período agroexportador até a fase de consolidação monopólica. Além disso, é conduzido, desde sua origem, pelo pacto de dominação estruturado pela articulação entre interesses agrários tradicionais e a burguesia industrial, incorporando os setores populares de forma seletiva.

Portanto, a linha de análise proposta entende que as mudanças processadas no aparato do Estado respondem ao movimento global do capitalismo dependente, devendo ser entendidas sob esse prisma, e não como um processo de racionalização da administração.

Neste sentido, consideramos que ocorre uma imbricação dialética entre "patrimonialismo" e "burocracia" (SOUZA FILHO, 2011), derivada do processo de desenvolvimento do capitalismo dependente a partir de um pacto de dominação que requer a manutenção dos elementos tradicionais da administração. Assim, a ideia básica aqui presente resume-se no entendimento de que o aparato do Estado dependente, enquanto administração pública, nasce, desenvolve-se e se consolida a partir de uma espinha dorsal que combina patrimonialismo e burocracia, configurando uma unidade contraditória, coerente com a particularidade do capitalismo dependente. Dessa forma, a gênese e a estrutura da ordem administrativa do aparato do Estado dependente se fundam no patrimonialismo e na burocracia. Isto não acontece porque seja forjada uma dicotomia entre o "velho" e o "novo", entre o "atraso" e o "moderno", mas sim devido à necessidade de objetivar a dominação das classes dominantes (proprietários rurais e burguesia), a partir do momento em que ocorre a passagem da sociedade 


\section{ADVistg all paUtg}

\} FUNDO PÚBLICO E POLÍTICAS SOCIAIS - SOUZA FH., R. \}

DOI: 10.12957/REP.2016.25401

colonial para uma sociedade nacional capitalista, o que implicou na existência de um sistema tradicional escravista/semiescravista e um sistema capitalista emergente, articulados intensivamente.

O modelo administrativo do aparato do Estado dependente, cunhado pelo processo de industrialização a partir dos anos 1930/1940, não se constitui como um modelo de tipo racional-legal que encontra obstáculos para ser implementado. O modelo proposto é de manutenção da imbricação do patrimonialismo com a burocracia, a fim de manter o pacto de dominação entre os interesses oligárquicos e os da burguesia industrial emergente, porém sob a ampliação dos mecanismos de tipo racional-legal, por conta da necessidade de implementação do projeto de industrialização e urbanização dependente. Em outras palavras, o projeto de industrialização, em sua dinâmica dependente, não apresenta uma proposta de suprimir os traços tradicionais do aparato do Estado para constituir um modelo puro burocrático weberiano.

Entendemos que, do ponto de vista estrutural, é nessa dinâmica de funcionamento do aparato do Estado dependente que se encontra a chave para explicação do baixo índice de institucionalidade desse aparato estatal e de seu alto índice de corrupção.

\subsection{Estado dependente e seu aparato: impactos na dinâmica do fundo público e das políticas sociais}

A partir da dinâmica do capitalismo dependente, a determinação estrutural e central que impacta a aplicação do fundo público realizada pela intervenção estatal está relacionada à necessidade de compensar a transferência de valor através de recursos públicos. Ou seja, como parte do excedente produzido pelos países dependentes é transferido para os países centrais, há necessidade de o capital compensar essa perda. Uma parcela dessa compensação, como vimos, é realizada estruturalmente pela superexploração. No entanto, outra parcela é compensada pelo fundo público constituído pelo Estado. Dessa forma, também estruturalmente, há necessidade de o Estado dependente suprir essa demanda do capital, seja para compensar a transferência de valor, seja para subsidiar o processo de industrialização no quadro tardio da expansão das relações capitalistas dos países periféricos.

Em relação a este último aspecto (processo de industrialização), convém sinalizar que Marx (1996a, p. 423), ao tratar do capital inicial necessário para começar um investimento, indica que esse valor "varia em diferentes graus de desenvolvimento da produção capitalista e, dado o grau de desenvolvimento, é diferente nas diferentes esferas da produção, conforme as condições técnicas específicas de cada uma". Tal situação, conforme ressalta o autor, leva o Estado a subsidiar determinadas iniciativas 


\section{hevistg eml pallg}

\} FUNDO PÚBLICO E POLÍTICAS SOCIAIS - SOUZA FH., R. \}

DOI: $10.12957 / R E P .2016 .25401$

particulares, na medida em que não se encontram capitais disponíveis suficientes "em mãos de indivíduos isolados". Este quadro se intensifica ao considerarmos a condição de inserção dos países dependentes na dinâmica do capitalismo tardio, exigindo que parte do fundo público seja destinada à expansão das relações capitalistas, independente da transferência de valor que ocorre devido à situação de dependência.

A partir destas considerações, tendo em vista a proposta de BresserPereira (1982) para análise do orçamento público e as determinações destacadas do capitalismo dependente e do seu Estado, além do aparato estatal correspondente, podemos, de forma breve e preliminar, indicar algumas hipóteses sobre os impactos desses elementos na estrutura do fundo público dos países dependentes.

Do ponto de vista da despesa, até a fase da consolidação da industrialização latino-americana (anos 1960/1970) ${ }^{11}$, podemos inferir que o Estado dependente deveria destinar, prioritariamente, os recursos públicos para os seguintes itens: subsídios à acumulação privada $(\mathrm{S})$, acumulação estatal (A) e consumo social de luxo (UL).

Como já ressaltado, os subsídios à acumulação privada seriam necessários para compensar a transferência de valor que se efetiva através do intercâmbio desigual entre os países dependentes e os países centrais, seja na fase agroexportadora, seja na fase industrial. Tais subsídios, pela lógica da dependência, tenderiam a se concentrar em: a) subsídios ao crédito, para viabilizar a acumulação no quadro de perda de mais valor e complementar a compensação realizada pela superexploração da força de trabalho; b) aporte ao desenvolvimento da infraestrutura, que contribuiria com a redução dos gastos com os bens de produção necessários para a produção de bens de consumo de luxo, eixo central da acumulação em conjunto com os bens primários voltados para a exportação, além de melhorar, também, a circulação de bens de luxo destinados ao mercado interno ${ }^{12}$; c) venda de bens produzidos pelo Estado a preço subsidiado e compra de mercadorias e serviços pelo Estado para garantir a realização da produção privada.

As despesas com acumulação estatal seriam necessárias, pois os preços subsidiados para apoiar a acumulação privada afetariam os lucros das empresas do Estado. Nesse sentido, para viabilizar a reprodução da acumulação das unidades produtivas estatais, o Estado dependente teria que compensar essa perda com recursos públicos orçamentários.

Fariam parte da despesa do item bens de consumo social de luxo: gastos com infraestrutura urbana (pavimentação, iluminação e saneamento

\footnotetext{
${ }^{11}$ Para o período pós-1980, principalmente os anos de 1990 e 2000, é necessário ponderar a partir da nova fase monopólica do capitalismo baseado na reestruturação do capital e do mundo do trabalho, hegemonizado pelas finanças.

${ }^{12}$ A ruptura do ciclo do capital, que faz com que os trabalhadores não se transformem em consumidores, potencializa a intervenção do Estado no campo dos bens destinados à reprodução do capital e ao consumo de luxo. "Esta determinação específica será decisiva para o deciframento das contradições que cercam o campo das políticas sociais na Ámérica Latina" (PAIVA; OURIQUES, 2009, p. 125).
} 


\section{ADVistg all paUtg}

\} FUNDO PÚBLICO E POLÍTICAS SOCIAIS - SOUZA FH., R. \}

DOI: $10.12957 /$ REP.2016.25401

público como infraestrutura para a construção de moradias de luxo), para atendimento das demandas das altas camadas da burocracia pública e privada, da classe capitalista e da oligarquia agrária; construção da base para o desfrute dos bens de luxo (rodovias para usar os automóveis, aeroportos para facilitar as viagens turísticas...); e bens sociais que seriam destinados preferencial e prioritariamente a tais classes, em especial, a educação pública de qualidade.

Cabe fazer uma pequena observação em relação aos gastos de segurança e administração. A expansão desses gastos, além de garantir a manutenção da ordem, deveria ser realizada na medida do crescimento da intervenção do Estado e serviria, em princípio, como forma de gerar emprego para camadas médias da população que ingressariam no sistema como consumidores de bens de luxo, atendendo à necessidade de ampliação e fortalecimento do mercado interno desses bens.

Se esses são os principais itens de despesa do fundo público necessários para garantir estruturalmente o processo de reprodução das relações de dependência, a despesa destinada ao consumo social básico tem que ser restringida ${ }^{13}$, mesmo porque a base de arrecadação, no quadro da industrialização dependente, é restrita, tanto do ponto de vista do capital, quanto do trabalho. A restrição da base de arrecadação, do ponto de vista do capital, estrutura-se devido à necessidade de se complementar a compensação da transferência do valor, ocorrendo, portanto, a redução da disponibilidade de mais valor para a constituição do fundo público. Do ponto de vista do trabalho, a restrição está relacionada à presença da superexploração; assim, a possibilidade de taxação dos trabalhadores também é reduzida, já que a base salarial está aquém da necessidade de reprodução de sua força de trabalho.

A equação final que incide sobre o fundo público, a partir dessas condições estruturais, tende a gerar desequilíbrio fiscal devido à restrição da arrecadação e à necessidade de intervenção do Estado para viabilizar a produção e reprodução das relações sociais do capitalismo dependente.

Tal desequilíbrio - na medida em que a arrecadação é restringida (tanto na esfera do capital, quanto na do trabalho) e os gastos tendem a ser maiores nos itens UL, G, S e A, em detrimento de UB - produz uma tendência à concentração de renda nos países dependentes. Essa hipótese está indicada, mas não desenvolvida ou esboçada, pelo menos como formulação lógico-abstrata, no trabalho de Bresser-Pereira (1982).

Em relação às determinações do fundo público enquanto constituído por um mix de valor e antivalor (OLIVEIRA, 1998b), as considerações tratadas acima indicam a hipótese de que, no capitalismo dependente, o

\footnotetext{
${ }^{13}$ Paiva, Rocha e Carraro (1998, p. 165), a partir da categoria excedente, chegam à mesma conclusão: "no caso latinoamericano, é parca a fração do excedente econômico do capital utilizado para sustentar o financiamento das políticas sociais".
} 


\section{ApVistg enl paltg}

\} FUNDO PÚBLICO E POLÍTICAS SOCIAIS - SOUZA FH., R. \}

DOI: $10.12957 /$ REP.2016.25401

quantum da fração valor do fundo público é substantivo devido aos gastos realizados com a acumulação estatal (A). Em relação ao antivalor, as despesas destinadas ao subsídio à acumulação privada (S) referem-se ao aporte ao capital constante. Contribuem, assim, para complementar a compensação da transferência de valor, propiciando a redução da inversão privada para a realização da reprodução ampliada, o que permite contrabalançar a perda de valor e viabilizar a taxa de lucro capitalista.

O outro gasto que compõe o antivalor diz respeito àqueles destinados à reprodução da força de trabalho, ou seja, os gastos com consumo social básico (UB). Como vimos, esse gasto é restrito. Assim, nos países dependentes, tende-se a não produzir antimercadorias sociais (serviços sociais públicos e gratuitos que compõem o salário indireto do trabalhador).

A fração do antivalor, portanto, que é significativa na lógica da dependência, é apenas a que incide sobre o capital constante e que alimenta o processo de valorização do valor. Dessa forma, não se realiza o fortalecimento do elemento contraditório do processo que se expressa na fração destinada à reprodução da força de trabalho. Dessa maneira, a contradição que o antivalor pode processar sobre a fração do valor, constitutiva do fundo público, e sobre o processo de valorização em seu conjunto, reduz-se sensivelmente, não possibilitando o movimento dialético em que a partir do antivalor se tensionaria o valor na perspectiva da produção de uma sociabilidade fundada no não valor (OLIVEIRA, 2001).

\section{Considerações finais}

O quadro exposto aponta para a baixa condição de vida da classe trabalhadora, gerando aumento das necessidades para sua reprodução social e uma restrição do fundo público para o desenvolvimento de políticas sociais. Consideramos que tais elementos conformam as determinações objetivas centrais que fundamentam a precarização das políticas sociais nos países periféricos.

Sinteticamente, podemos dizer que a hipótese construída ao longo do trabalho, extraída da dinâmica do capitalismo dependente, indica: que a fração do valor constitutiva do fundo público é significativa; que o elemento antivalor destinado ao capital constante é superior ao destinado ao capital variável; que há baixa produção de antimercadorias sociais que atingem o capital variável; e que, nessas condições, o antivalor possui baixa potência para processar uma contradição significativa à fração do valor constitutiva do fundo público e ao processo de produção de valor.

Como decorrência de todo o movimento descrito anteriormente, do ponto de vista da arrecadação, efetiva-se uma tendência de produção, nos países dependentes, de políticas tributárias regressivas, mesmo em condições de baixa capacidade de tributação sobre o trabalho devido à 


\section{heVistg all pautg}

\} FUNDO PÚBLICO E POLÍTICAS SOCIAIS - SOUZA FH., R. \}

DOI: 10.12957/REP.2016.25401

superexploração. Assim, os recursos que poderiam ser disputados para o desenvolvimento de políticas sociais são reduzidos estruturalmente. Tal fato nos parece determinante, do ponto de vista objetivo, para compreendermos a conformação das políticas sociais dos países dependentes, que não se desenvolveram enquanto políticas universalistas, públicas e gratuitas de reponsabilidade do Estado e de direito de cidadania. 


\section{ApVistg enl paltg}

\} FUNDO PÚBLICO E POLÍTICAS SOCIAIS - SOUZA FH., R. \}

DOI: $10.12957 /$ REP.2016.25401

\section{Referências}

AMARAL, M. S.; CARCANHOLO, M. D. Superexploração da força de trabalho e transferência de valor: fundamentos da reprodução do capitalismo dependente. In: FERREIRA, C.; OSORIO, J.; LUCE, M. S. (Org.). Padrão de reprodução do capital. São Paulo: Boitempo. 2012.

BARAN, P.; SWEEZY, P. El capital monopolista. México: Siglo XXI. 1982. BEHRING, E. Política social no capitalismo tardio. São Paulo: Cortez. 1998. BEHRING, E. Rotação do capital e crise: fundamentos para compreender o fundo público e a política social. In: BEHRING, E. et al. (Org.). Financeirização, fundo público e política social. São Paulo: Cortez. 2012.

BOSCHETTI, I.; BEHRING, E. Política social: fundamentos e história. São Paulo: Cortez. 2006.

BRESSER-PEREIRA, L. C. Despesas do Estado, repartição e valor. Revista de Economia Política, São Paulo: Centro de Economia Política, vol. 2/3. 1982.

CARCANHOLO, M. D. (Im)precisões sobre a categoria superexploração da força de trabalho. In: ALMEIDA FILHO, N. (Org.). Desenvolvimento e dependência: cátedra Ruy Mauro Marini. Brasília: Ipea. 2013.

HEGEL, G. W. F. Princípios da filosofia do Direito. São Paulo: Martins Fontes. 1997.

IAMAMOTO, M. A questão social no capitalismo. Temporalis, Revista da Associação Brasileira de Ensino e Pesquisa em Serviço Social, Brasília: Abepss, ano II, n. 3. 2001.

MANDEL, E. O capitalismo tardio. São Paulo: Abril Cultural. 1982.

A teoria do valor-trabalho e o capitalismo monopolista. 2010.

Disponível em: <https://www.marxists.org/portugues/mandel/1967/12/ teoria.htm>. Acesso em: 20 jun. 2015.

MARINI, R. M. O ciclo do capital na economia dependente. In: FERREIRA, C.; OSORIO, J.; LUCE, M. S. (Org.). Padrão de reprodução do capital. São Paulo: Boitempo. 2012.

. Dialética da dependência. In: TRASPADINI, R.; STEDILE, J. P. (Org.). Ruy Mauro Marini: vida e obra. São Paulo: Expressão Popular. 2005.

. Plusvalía extraordinária y acumulación de capital. Cuadernos Políticos, México: Editoria Era, n. 20. 1979.

MARINI, R. M. Las razones del neodesarollismo (respuesta a F. H. Cardoso y J. Serra). Revista de Sociologia, México: Unam. 1978.

MARTINS, C. E. Globalização, dependência e neoliberalismo na América Latina. São Paulo: Boitempo. 2011. 


\section{ApVistg all paUtg}

\} FUNDO PÚBLICO E POLÍTICAS SOCIAIS - SOUZA FH., R. \}

DOI: $10.12957 /$ REP.2016.25401

MARX, K. O capital: crítica da economia política. Livro Terceiro, tomo II. São Paulo: Nova Cultural. 1986.

. O capital: crítica da economia política. Livro Primeiro, tomo I. São Paulo: Nova Cultural. 1996a.

. O capital: crítica da economia política. Livro Primeiro, tomo II. São Paulo: Nova Cultural. 1996b.

Salário, preço e lucro. In: O capital: crítica da economia política. Livro Primeiro, tomo I. São Paulo: Nova Cultural. 1996c.

. Para a crítica da economia política. In: Os pensadores. São Paulo: Nova Cultural. 1996d.

NETTO, J.P. Cinco notas a propósito da "questão social". In: Temporalis. Brasília: ABEPSS, Grafline, 2001

OLIVEIRA, F. O surgimento do antivalor. In: Os direitos do antivalor: a economia política da hegemonia imperfeita. Petrópolis: Vozes. 1998a.

. A economia política da social-democracia. In: Os direitos do antivalor: a economia política da hegemonia imperfeita. Petrópolis: Vozes. 1998b.

- Nós que combatíamos tanto: a economia política da cidadania. Revista da Sociedade Brasileira de Economia Política, Rio de Janeiro: Sociedade Brasileira de Economia Política. 2001.

OSORIO, J. Explotación redoblada y actualidad de la revolución: refundación societal, rearticulación popular y nuevo autoritarismo. México: Editorial Itaca. 2009.

. Estado, biopoder, exclusión: análisis desde la lógica del capital. Barcelona: Anthropos Editorial; México: Universidad Autónoma Metropolitana, Unidad Xochimilco. 2012.

. Fundamentos da superexploração. In: ALMEIDA FILHO, N. (Org.). Desenvo/vimento e dependência: cátedra Ruy Mauro Marini. Brasília: Ipea. 2013.

- Estado, reproducción del capital y lucha de clases: la unidad económica/política del capital. México: Universidad Autónoma Metropolitana. 2014.

PAIVA, B.; OURIQUES, N. Uma perspectiva para as políticas sociais: quão distante está o horizonte? In: BORGES, L. F.; MAZZUCO, N. G. (Org.). Democracia e políticas sociais na América Latina. São Paulo: Xamã. 2009.

PAIVA, B; ROCHA, M.; CARRARO, D. Política social na América Latina: ensaio de interpretação a partir da Teoria Marxista da Dependência. SER Social, Revista do PPGPS, Brasília: UNB. 1998. 


\section{hevistg all pantg}

\} FUNDO PÚBLICO E POLÍTICAS SOCIAIS - SOUZA FH., R. \}

DOI: 10.12957/REP.2016.25401

SALVADOR, E. Fundo público e seguridade social no Brasil. São Paulo: Cortez. 2010.

SOUZA FILHO, R. Gestão pública e democracia: a burocracia em questão. Rio de Janeiro: Lumen Juris. 2011. . Fundo público e políticas sociais no capitalismo: considerações teóricas. In: Serviço Social e Sociedade, n. 126. São Paulo: Cortez. 2016.

Recebido em 20 de dezembro de 2015.

Aprovado para publicação em 19 de junho de 2016.

DOI: 10.12957/rep.2016.25401

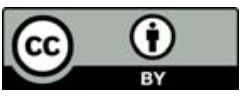

A Revista Em Pauta: Teoria Social e Realidade Contemporânea está licenciada com uma Licença Creative Commons Atribuição 4.0 Internacional. 